THE unofficial Moscow seminar on "Collective Phenomena and the applications of physics to other fields of science", scheduled for July 1-5, 1974 now must pass into history as "the seminar that never was". With the arrest on Friday June 28 of Sinologist Vitali Rubin, it would seem that all leading members of the organising committee were in custody at the time of going to press. According to a cousin of Professor Mark Azbel, the arrested organisers are held outside Moscow, in detention centres which have previously been used for the temporary removal of dissidents from eirculation. The centres mentioned are at Volokalansk and Serpukhov-the second showing a certain irony on the part of the authorities. Those intending participants not in custody are under virtual house arrest with police cars parked outside.

\section{Seminar that never was}

On hearing of the arrests, Professor Edward Stern, one of the three international secretaries of the seminar, began an intensive campaign in Washington to effect the scientists' release. A delegation from the intending participants met Senators Jackson, Javits and Ribicoff, who undertook to send a telegram to Dr Kissinger, asking for their release. They also met Senator Hartke of Indiana who claims to be on good terms with Brezhnev, and who promises to intercede personally on their behalf. Acting Secretary of State Sisco also showed considerable interest in the plight of the scientists, and undertook to bring it to Dr Kissinger's attention. Eleven Nobel Laureates endorsed the principle, which has been conveyed to $\mathrm{Mr}$ Nixon in Moscow, that the right of scientists to emigrate without harassment should be written into any bilateral agreement between the United States and USSR.

Meanwhile, it has been learned that Mrs Nina Voronel was informed on Saturday June 29 that the group will be released after the scheduled seminar dates have safely passed. What their subsequent fate will be remains uncertain. One of them, CorrespondingAcademician Venyamin Levich, has, however, now been granted permission to emigrate "at the end of 1975", while his sons Venyamin and Aleksandr can leave at the end of this year. If this is an omen of events to come, the ill-fated Seminar will not have been convened in vain.
IT is ten years since the June 1964 elections to the Soviet Academy of Sciences which marked the beginning of the end of Lysenkoism and the reintroduction of Mendelian genetics in the Soviet Union. Although the theoretical and practical significance Russians are usually eager to mark any for the development of agriculture, significant anniversary, this particular medicine and a number of branches of one is not liable to receive the usual industry", Nevertheless, it is found that acclamation of celebratory meetings "the general level and scale of research and publications. Nevertheless, a recent on molecular biology and molecular decree of the Central Committee of genetics in our country is still insuffithe Communist Party of the USSR cient. There are only a few highly and the Council of Ministers of the USSR does, in oblique fashion, form a kind of epitaph to the Lysenko period, by indicating the harm done to the development of Soviet science by almost a quarter of a century of opting out of world trends in research in genetics and molecular biology.

The Decree, published on May 21, 1974 , deals with "the question of measures to accelerate the development of molecular biology and molecular genetics and to use their achievements in the national economy". It begins with the face-saving observation that "in recent years, on the basis of the wide use in biology of the achievements of chemistry, physics and mathematics, it has become possible to investigate the molecular mechanisms of the most important processes determining the existence and development of living matter". (This would logically imply that the earlier decision, in 1948 , to stop all genetic research and, on the orders of the MGB-now the KGB-to destroy all Drosophila held in laboratories by drowning them in boiling water, was quite 'correct'; the necessary achievements in other fields had not yet been reached.)

Now, however, "fundamental discoveries in this branch of the natural sciences" have been made (it is not said by whom), which "have great

\section{Epitaph to Lysenkoism qualified specialists making ready in this field. There are serious deficiencies in the organisation of the production of special scientific instruments and high class apparatus, the necessary range of chemical reagents, materials and biological preparations."}

Accordingly, since "the Central Committee of the Communist Party of the Soviet Union and the Council of Ministers of the USSR consider that the achievement in the shortest possible time of the foremost level of development of molecular biology, molecular genetics and other branches of natural science immediately connected with the study of the physico-chemical principles of life phenomena" constitutes "one of the most important problems of Soviet science at the present time", the appropriate steps are to be taken. The Academy of Sciences, the State Committee for Science and Technology, the State Planning Committee and the various ministries and departments are charged with "ensuring the necessary rate of development of these sciences and a wide use of their achievements in agriculture, medicine and industry", with "strengthening the basic trends of fundamental research", and also with drawing up a concrete programme of research and design for 1974-80. This last clause is extremely signi- passport. ficant-the new policy becomes effective immediately, without waiting, as would normally be expected, for the beginning of the next five-year plan in 1976. Since the logistics of implementing such mid-plan changes of policy in the framework of the rigid quinquennial budgeting of financial and manpower resources are considerable, it seems clear that what is involved is not only a change of planning policy, which could have waited another 18 months, but something close to panic measures.

The practical details contained in the Decree are sparse, as always. We learn, however, that a special Interdepartmental Scientific and Technical Council has been formed to coordinate research in this field, that means have been assured for the training of specialists, scientists and instructors, that new scientific research establishments and training colleges are to be opened and existing ones expanded, and also that "research bases" are to be constructed. The production of the required instruments, reagents and other necessities is to be "considerably expanded".

The Decree ends with the conventional expression of the confidence of the Central Committee and Council of Ministers that all persons and organisations concerned will carry out their appointed tasks in this new expansion of Soviet science in the fields of molecular biology and molecular genetics. In this atmosphere of all shoulders to the wheel, it seems unfortunate, for the Soviet authorities, that they can no longer call on the help and assistance of the chronicler of the Lysenkoist "pseudoscience", who did so much towards its overthrow -Zhores A. Medvedev, who, a year ago, they saw fit to deprive of his 